\title{
The Influence of Refrigerants on Energy Indicators of Hermetic Compressors
}

\author{
Aleksandr Vasilievich Maksimov, Larisa Vladimirovna Sumzina \\ Russian State University of Tourism and Service, Moscow, Russia
}

\begin{abstract}
This work is devoted to determination of thermal energy indicators of hermetic compressor operating with R600a and $\mathrm{R} 134 \mathrm{a}$ refrigerants. It has been mentioned that the operation efficiency and quality of refrigerating machines are mainly determined by technical-economic and operation properties of compressor. The main properties of hermetic refrigerator compressors, determining their technical level, are cooling factor, sound power level, and weight. Despite numerous experiments, up till now the main attention has been paid to analysis and reduction of bulk losses, and some scientific problems aimed at analysis of temperature field, bulk and energy indicators of hermetic compressors applying R600a and R134a refrigerants have not been studied in details. It has been demonstrated that development and solution to the issue of material processing were based on theoretical and experimental methods, including the method of system and structural analysis. The thermal energy indicators of hermetic compressors have been determined by means of adiabatic calorimetry. It has been experimentally determined that application of R600a refrigerant reduces temperature field of compressor by $20 \ldots 22^{\circ} \mathrm{C}$ in comparison with $\mathrm{R} 134 \mathrm{a}$ refrigerant. On the basis of experiments with hermetic compressor, it has been established that application of R600a refrigerant leads to decrease in consumed capacity by $85 \%$ in average, decrease in refrigeration capacity by $33 \%$, increase in cooling factor by $27.6 \%$.
\end{abstract}

Key words: hermetic compressor, refrigerant, thermal energy indicators.

\section{INTRODUCTION}

The operation efficiency and quality of household refrigerating machines are mainly determined by technical-economic and operation properties of compressor $[1,2]$. Improvement of hermetic compressor as the most important and complicated element of household refrigerator attracted the main attention [3]. This is stipulated by the fact that the compressor indications determine reliability, life-time, the level of noise and vibrations of refrigerating machine $[4,5]$.
Numerous $R \& D$ projects are devoted to analysis and improvement of refrigerator hermetic compressors $[5,6,7,8$, $9,10]$.

With the increase in production and expansion of functional possibilities of household refrigerators, the improvement of hermetic compressor became especially important $[11,12]$.

The main properties of hermetic refrigerator compressors, determining their technical level, are cooling factor, sound power level, and weight [13-15].

The technical level of hermetic compressors is being improved mainly in four areas [16-19]:

- increase in cooling capacity per unit volume;

- decrease in consumed power per unit volume;

- decrease in sound power level;

- decrease in weight and dimensions per unit volume.

Despite numerous experiments, up till now the main attention has been paid to analysis and reduction of bulk losses, and some scientific problems aimed at analysis of temperature field, bulk and energy indicators of hermetic compressors applying R600a and R134a refrigerants have not been studied in details.

\section{METHODS}

The development and solution to the issue of material processing were based on theoretical and experimental methods, including the method of system and structural analysis.

The thermal energy indicators of hermetic compressors have been determined by means of adiabatic calorimetry.

\section{RESULTS AND DISCUSSION}

Operation of hermetic refrigerator compressor is stipulated by peculiar conditions developed in closed cycle of refrigerator. Compressor carries out compressing and forcing of refrigerant vapors in wide pressure range of condensation and boiling, which are determined by the required temperature limits of cooling cycle and thermophysical properties of applied working medium. 
For maximum approximation of experimental conditions to actual operation, accurate measurement of minor flow rates of refrigerant and determination of properties of hermetic compressors, specialized testing methods were developed on the basis of adiabatic calorimetry; these methods are successfully applied $[14,15]$.
The main thermal energy properties of the compressors were determined in accordance with the recommendations [14, $15]$.

The influence of the applied refrigerant on temperature field of hermetic compressors (Figure 1) was determined experimentally.

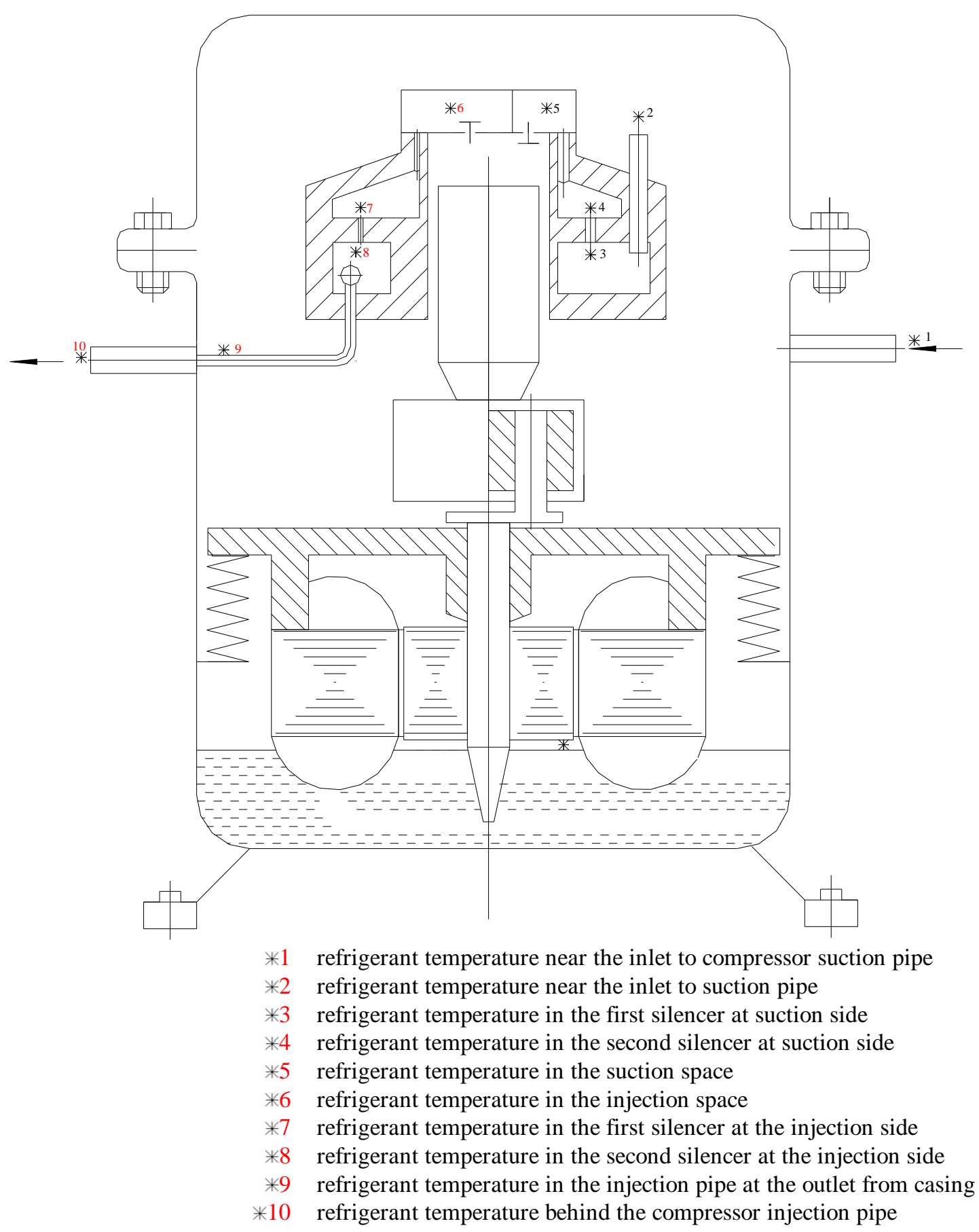

Figure 1: Schematic view of compressor indicating locations of thermocouples 
The experimental results of the piston compressor are illustrated in Figure 2.

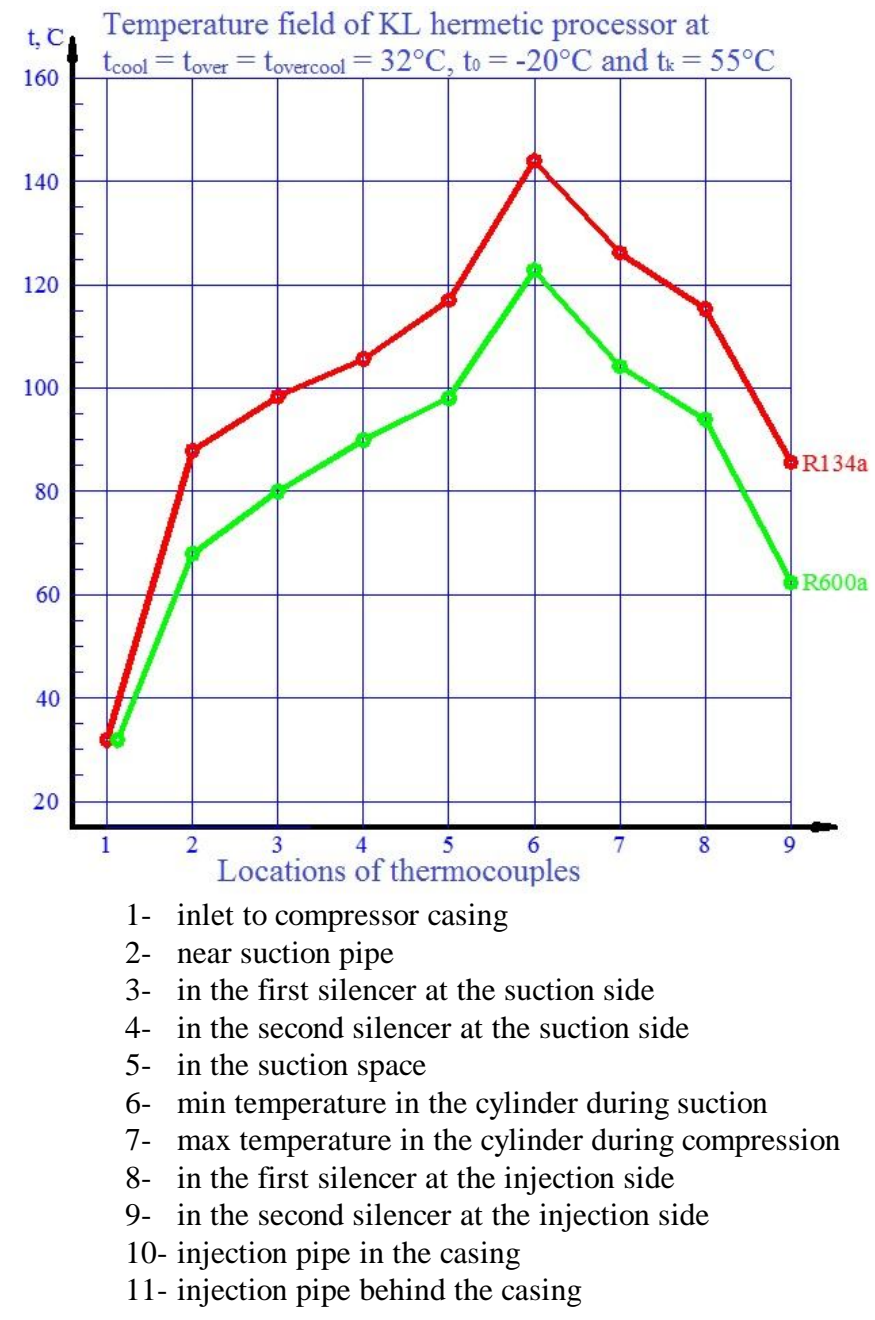

Figure 2: Temperature field of hermetic compressor at $\mathrm{t}_{\text {cool }}=\mathrm{t}_{\text {over }}=\mathrm{t}_{\text {overcool }}=32^{\circ} \mathrm{C}, \mathrm{t}_{0}=-20^{\circ} \mathrm{C}$ and $\mathrm{t}_{\mathrm{k}}=55^{\circ} \mathrm{C}$

The experiments were carried out using calorimetry test rig allowing to determine the bulk capacity of compressor by two independent methods: on the basis of thermal balance of condenser and thermal balance of calorimeter $[14,15]$. In the first case, mass flow rate and temperature of cooling water are recorded at inlet and outlet from condenser, the temperature of refrigerant at inlet and outlet from condenser is determined; and in the second case, the power to electric heater of calorimeter, the pressure and temperature of refrigerant at inlet and outlet are measured. In the bottom part of calorimeter filled with refrigerant, the electric heater is installed. The vapor generated during boiling is condensed on outer surface of vaporizer. During testing the heater power is adjusted so that the pressure of secondary refrigerant is constant, that is, the amount of generated cold is equal to the amount of supplied heat.

Comparative experiments with the hermetic compressor have demonstrated that application of R600a refrigerant reduces the temperature field of compressor by $20 \ldots 22^{\circ} \mathrm{C}$ in average in comparison with R134a refrigerant (Figure 2).

The experiments with KL compressors were carried out in accordance with the procedure described in section 6.2.

The influence of the applied refrigerants on thermal energy properties indications of compressor was determined by measurements of power consumed by compressor, cooling capacity of compressor, mass flow rate of refrigerant.

The experiments were carried out at two temperatures of condensation: $t_{k}=45^{\circ} \mathrm{C}$ and $t_{k}=55^{\circ} \mathrm{C}$ for two refrigerants: R600a and R134a.

The results of comparisons of compressor with various refrigerants are illustrated in Figures. 3-8.

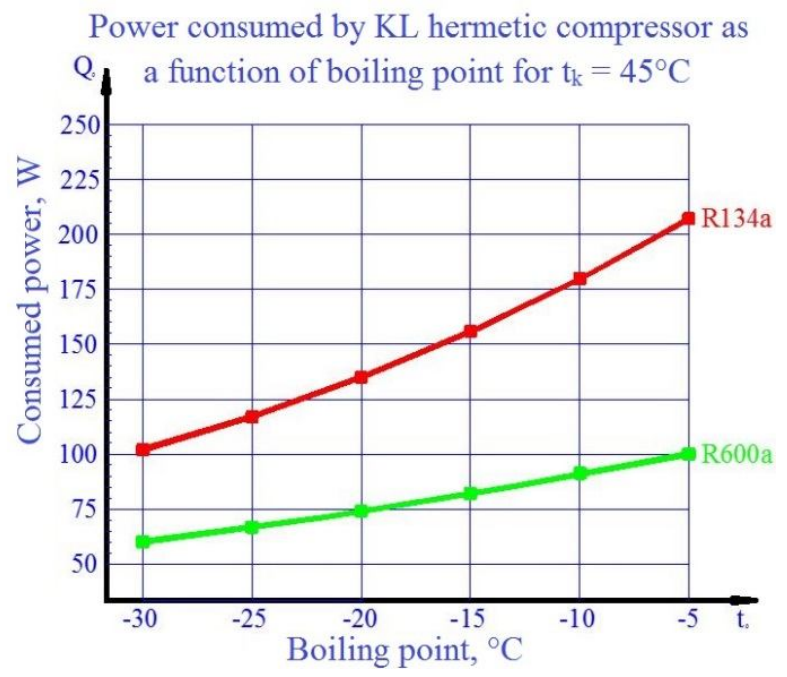

Figure 3: Power consumed by hermetic compressor as a function of boiling point for $t_{k}=45^{\circ} \mathrm{C}$

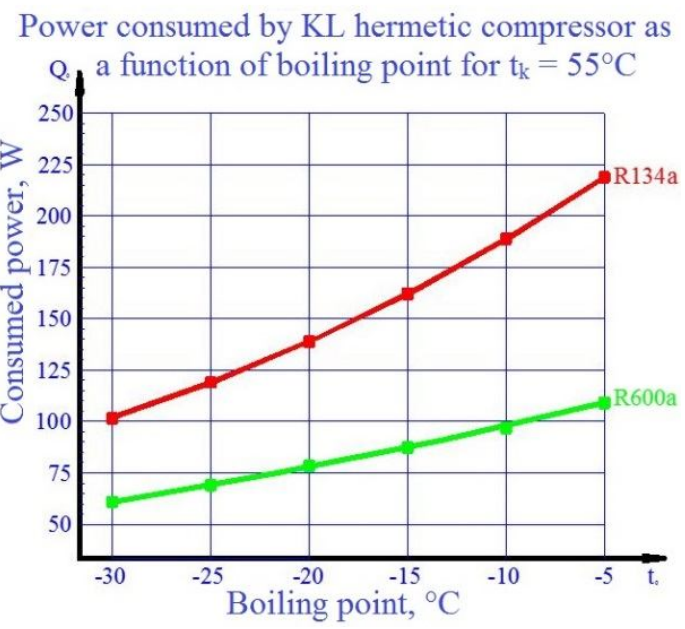

Figure 4: Power consumed by hermetic compressor as a function of boiling point for $\mathrm{t}_{\mathrm{k}}=55^{\circ} \mathrm{C}$ 
Aleksandr Vasilievich Maksimov et al., International Journal of Emerging Trends in Engineering Research, 8(7), July 2020 , 3305 - 3309

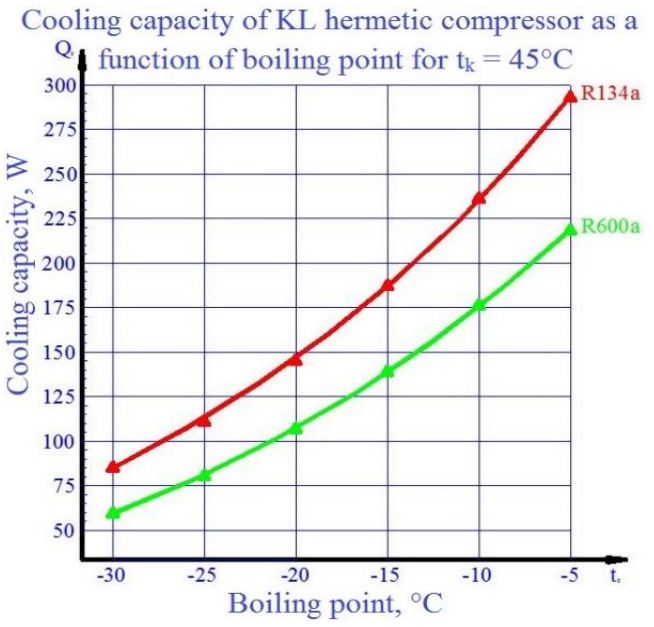

Figure 5: Cooling capacity of hermetic compressor as a function of boiling point for $\mathrm{t}_{\mathrm{k}}=45^{\circ} \mathrm{C}$

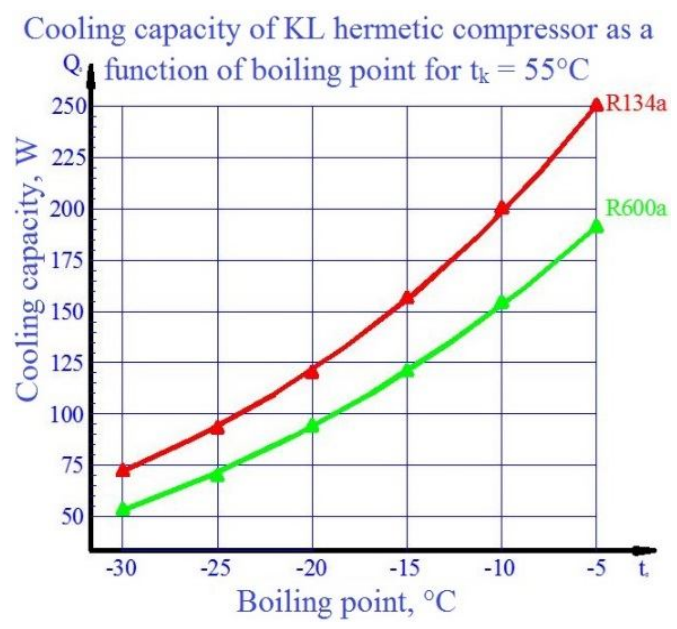

Figure 6: Cooling capacity of hermetic compressor as a function of boiling point for $\mathrm{t}_{\mathrm{k}}=55^{\circ} \mathrm{C}$

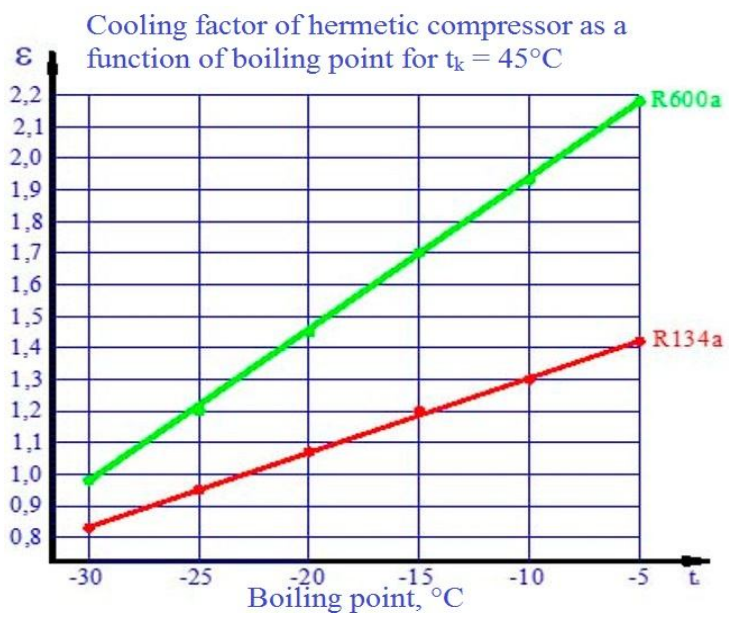

Figure 7: Cooling factor of hermetic compressor as a function of boiling point for $\mathrm{t}_{\mathrm{k}}=45^{\circ} \mathrm{C}$
Cooling factor of hermetic compressor as

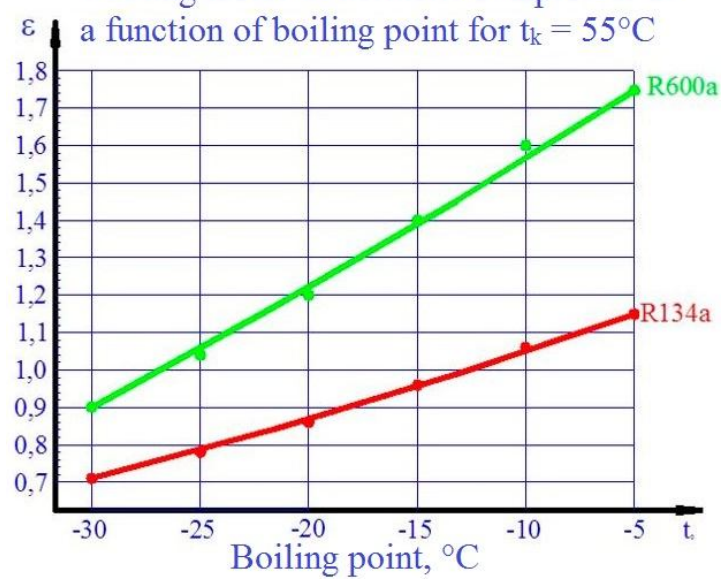

Figure 8: Cooling factor of hermetic compressor as a function of boiling point for $\mathrm{t}_{\mathrm{k}}=55^{\circ} \mathrm{C}$

Comparative analysis of the results illustrated in Figs. 3-8 has demonstrated that the cooling factor for R600a refrigerant is higher than that for R134a by 26.3...27.6\%.

The performed studies confirm the theoretical conclusions that the R600a refrigerant is superior to the R134a refrigerant under predefined constrained experimental conditions.

\section{CONCLUSION}

The analyzed trends of development of hermetic compressors for household refrigerators have demonstrated that they are aimed at improvement of technical level upon application of ozone-safe refrigerants R600a and R134a.

Comparative analysis of experimental results of hermetic compressor has confirmed theoretical conclusions and has revealed that application of R600a refrigerant reduces temperature field of compressor by $20 \ldots 22^{\circ} \mathrm{C}$ in comparison with R134a refrigerant.

Analysis of hermetic compressor has revealed that application of R600a refrigerant leads to decrease in consumed capacity by $85 \%$ in average, decrease in refrigeration capacity by $33 \%$, increase in cooling factor by $27.6 \%$.

\section{REFERENCES}

1. V.S. Reznikov, P.V. Romanov. Analiz metodov uvelicheniya energoeffektivnosti kompressionnykh kholodil'nikov [Improvement of energy efficiency of compressor refrigerators], Intellektual'nyi potentsial XXI veka: stupeni poznaniya, Vol. 23, pp. 143-146, 2014.

2. L.V. Sumzina, A.V. Maksimov. Analiz poter' eksergii v tsikle kompressionnogo bytovogo kholodil'nika [Analysis of exergy loss in a cycle of household compressor refrigerator]. Elektrotekhnicheskie $i$ informatsionnye kompleksy i sistemy, Vol. 8, No 1, pp. 37-39, 2012. 
3. B.S. Babakin, V.A. Vygodin. Bytovye kholodil'niki i morozil'niki [Household refrigerators and freezers], Kolos, Moscow, 2000.

4. W. Maake, H.-J. Eckert, J.L. Cauchepin. Le Pohlmann: manuel technique du froid, bases, composants, calculs, montage, conduite, maintenance des installations frigorifiques. Ivry-sur-Seine, 1993.

5. I.I. Videnov. Thermal processes in hermetic compressors. Synopsis, Cand. Thesis. Odessa, 1974.

6. A.V. Maksimov, V.V. Kolyada, Ya.A. Sirotenko. Zavisimost' pokazatelei termodinamicheskoi effektivnosti tsikla kholodil'nogo agregata ot temperatury pereokhlazhdeniya $v$ teploobmennike [Thermodynamic efficiency of refrigerator cycle as a function of overcooling temperature in heat exchanger], Elektrotekhnicheskie $i$ informatsionnye kompleksy $i$ sistemy, Vol. 8, No 2, pp. 60-64, 2012.

7. V.A. Pershin, A.G. Sapronov, K.A. Adigamov. Intensivnost' teplovykh potokov, kak kriterii otsenki effektivnosti kholodil'nogo tsikla [Intensity of heat glow as a criterion of efficiency estimation of refrigerating cycle], Inzhenernyi vestnik Dona, Vol. 19, No 1, pp. 185-187, 2012.

8. A. Cavallini, D. Del Col, L. Rossetto. Heat transfer and pressure drop of refrigerants in minichannels (low charge equipment). International Journal of Refrigeration, Vol. 36, pp. 287-300, 2013.

https://doi.org/10.1016/j.ijrefrig.2012.11.005

9. S.V. Shaytura, A.M. Minitaeva, K.M. Ordov, V.V. Shaparenko. Virtual enterprises in a spatial economy, International Journal of Recent Technology and Engineering, Vol. 7 No 6, pp. 719-724, 2019.

10. R. Radermachev. Ausblick auf die Kalte-Klima-Warmepumpen Technik. Chillventa Cougvessing, Nuremberg, 2014.

11. A.Yu. Gamzayan. Improvement of thermal energy properties of household refrigerators by compressor cooling and additional overcooling of working medium: Cand. thesis: 05.02.13. South Russian State University of Economics and Serviceб Shakhty, 2006.

12. I.N. Krasnovskii. Decrease in energy consumption by household refrigerators during conversion to new refrigerants: Synopsis, Cand. thesis: 05.04.03. Odessa, 1997.

13. V.V. Levkin. Improvement of thermal energy properties of household refrigerators: Doctoral thesis: 05.02.13. Moscow State University of Service, Moscow, 2004.

14. A.V. Maksimov. Improvement of energy efficiency of household refrigerators with compressor cooling systems: Cand. thesis: 05.02.13. State academy of houses and services, Moscow, 1994.

15. A.I. Naberezhnykh, O.P. Golubev, A.V. Maksimov, S.P. Poserenin. Analiz raboty i rekomendatsii po povysheniyu osnovnykh pokazatelei kachestva germetichnykh khladonovykh kompressorov dlya bytovykh kholodil'nikov [Analysis of operation and recommendations on improvement of main quality indices of hermetic Freon compressors for household refrigerators]. Moscow Technological Institute, Moscow, 1985.

16. I.M. Kalnin', K.N. Fadekov. Otsenka effektivnosti termodinamicheskikh tsiklov parokompressionnykh kholodil'nykh mashin i teplovykh nasosov [Efficiency estimation of thermodynamic cycles of vapor compression refrigerators and heat pumps], Kholodil'naya tekhnika, Vol. 3, pp. 16-25, 2006.

17. P.I. Plastinin. Teoriya i raschet porshnevykh kompressorov [Theory and analysis of piston compressors]. Agropromizdat, Moscow, 1987.

18. Chang Youg Park, PegaHrnjak. CO2 flow condensation heat transfer and pressure drop in multi-port microchannels at low temperatures, International Journal of Refrigeration, Vol. 32, pp. 1129-1139, 2009. https://doi.org/10.1016/j.ijrefrig.2009.01.030

19. E.W. Lemmon, M.L. Huber, M.O. McLinden. NIST Reference Fluid Thermodynamic and Transport Properties-REFPROP. Version 8.0. Gaithersburg, Maryland, 2007, 51 p. 